\title{
Korea's yin and yang
}

\section{Over the past few decades, South Korea has made impressive economic and scientific progress. Can the country maintain this fast pace?}

The tales of the two Korean countries, North and South, could hardly be more different. The North is a communist country that has severe problems in distributing sufficient food and energy to its population. The South, in contrast, has benefited from the peace following the Korean War. Its modern market economy, depending on statistics, ranks between 10 th to 15 th place in the world in terms of overall gross domestic product. As well as traditional industries such as steel, cars and shipbuilding, modern industries such as electronics contribute significantly to the country's wealth.

Scientifically, as Seoul National University's Dean of the College of Natural Sciences, Se-Jung Oh, points out, the total output in the number of scientific publications is in line with South Korea's economic strength ${ }^{1}$. However, there is a perception that the quality of publications falls below expectations, and the number of citations to papers from Korea remain low. Our own statistics seem to confirm this. Out of 685 manuscripts accepted for publication in Nature Materials over the past five years, only nine had the corresponding author based in South Korea. That number falls far behind Japan (64), but remains just ahead of China (seven, four of which were accepted in 2007).

This disparity between quantity and quality highlights a number of problems in the Korean academic infrastructure. Firstly, performance incentives at most institutions are partly based on the number of papers published, and are not necessarily related to the quality of the research. This pressure often leads to advances being published too soon - often ruling out later consideration in high-profile journals.

Furthermore, there seems to be too much focus on applied research rather than long-term fundamental research. According to Se-Jung Oh, only $10 \%$ of all

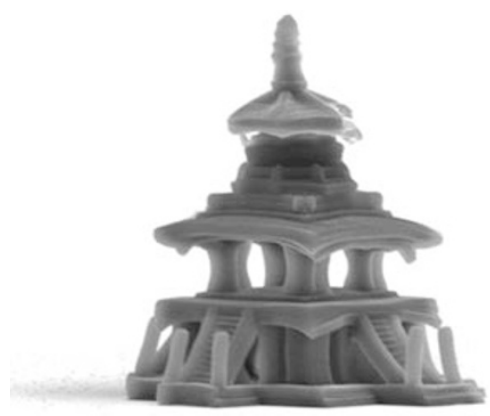

Modern Korean research. Shown here is a visually striking representation of the Dabotap pagoda at Bulguk temple transferred onto the microscale at KAIST ${ }^{4}$.

grant applications in basic sciences are approved, and overall spending is low. When visiting Korean universities, another problem becomes apparent - barriers between departments are typically too high, researchers are too isolated from each other and too few multidisciplinary research centres exist. This issue is also of concern to Ohjoon Kwon, head of research at the steel company POSCO. He too emphasizes the benefits of interdisciplinary research activities, even in a traditional industry such as steel making ${ }^{2}$. Finally, Korea only taps into half of its creative potential, as the percentage of women in research, about $10 \%$ of faculty, falls behind western averages.

Nevertheless, many of these structural problems are shared by other major countries. And despite such shortcomings, human capital seems not to be the problem. On the contrary, Korean scientists are highly qualified, often equipped with western PhD degrees and post-doc experience, and are extremely motivated in their research. Institutions such as the Pohang Light Source or the Asia-Pacific
Center for Theoretical Physics foster international relations. Overall, there is a tremendous drive to advance the quality of research, and certainly even more success can be expected.

However, a cloud remains over the Korean peninsula - issuing from North Korea. Whilst her leaders seem boisterous on the political stage, North Korea's general population remains insulated from any foreign influence, and living standards continue to drop below even basic levels. At the same time, POSTECH's president Chan-Mo Park agrees that it is important to keep the dialogue with North Korea open $^{3}$. The hope is that such dialogue will eventually build bridges between the countries, and recent indications of a détente on nuclear issues give reasons for hope. One promising initiative in the north is Pyongyang University of Science and Technology, which is scheduled to open its doors in the spring of 2008.

Interestingly, this university is sponsored internationally, and its president, Kim Chin Kyung, as well as Chan-Mo Park, who is scheduled to move there in October 2007, both have American passports. Indeed, this project might represent a promising avenue into North Korea - as long as North Koreans have access to the university.

All in all, it is our impression that South Korea's modern, forward-looking society and its very motivated and dynamic population should ensure that Korean science will further improve on the impressive scientific achievements of the past decades. We certainly hope to report some of these upcoming advances in these pages.

\footnotetext{
References

1. Oh, S.-J. Nature Mater. 6, 707-709 (2007).

2. Interview. Nature Mater. 6, 713 (2007)

3. Interview. Nature Mater. 6, 711-712 (2007).

4. Yang, D.-Y. et al. Appl. Phys. Lett. 90, 013113 (2007).
} 